\title{
Using the entomological inoculation rate to assess the impact of vector control on malaria parasite transmission and elimination
}

\author{
Ayesha M Shaukat*, Joel G Breman and F Ellis McKenzie
}

\begin{abstract}
Background: Prior studies have shown that annual entomological inoculation rates (EIRs) must be reduced to less than one to substantially reduce the prevalence of malaria infection. In this study, EIR values were used to quantify the impact of insecticide-treated bed nets (ITNs), indoor residual spraying (IRS), and source reduction (SR) on malaria transmission. The analysis of EIR was extended through determining whether available vector control tools can ultimately eradicate malaria.

Method: The analysis is based primarily on a review of all controlled studies that used ITN, IRS, and/or SR and reported their effects on the EIR. To compare EIRs between studies, the percent difference in EIR between the intervention and control groups was calculated.

Results: Eight vector control intervention studies that measured EIR were found: four ITN studies, one IRS study, one SR study, and two studies with separate ITN and IRS intervention groups. In both the Tanzania study and the Solomon Islands study, one community received ITNs and one received IRS. In the second year of the Tanzania study, EIR was $90 \%$ lower in the ITN community and $93 \%$ lower in the IRS community, relative to the community without intervention; the ITN and IRS effects were not significantly different. In contrast, in the Solomon Islands study, EIR was 94\% lower in the ITN community and 56\% lower in the IRS community. The one SR study, in Dar es Salaam, reported a lower EIR reduction (47\%) than the ITN and IRS studies. All of these vector control interventions reduced EIR, but none reduced it to zero.

Conclusion: These studies indicate that current vector control methods alone cannot ultimately eradicate malaria because no intervention sustained an annual EIR less than one. While researchers develop new tools, integrated vector management may make the greatest impact on malaria transmission. There are many gaps in the entomological malaria literature and recommendations for future research are provided.
\end{abstract}

\section{Background}

To fight malaria successfully, researchers must use current tools effectively and measure the impact of these tools precisely. This paper assesses the entomological inoculation rate (EIR) in relation to the major vector control interventions. EIR measures the intensity of malaria parasite transmission by anopheline vectors and vector control interventions are the only tools currently considered able to interrupt transmission. Vector control success against malaria is based on previous experiences in

* Correspondence: amsha2@bu.edu

${ }^{1}$ Division of International Epidemiology and Population Studies, Fogarty International Center, National Institutes of Health, Bethesda, MD, USA Full list of author information is available at the end of the article temperate climate countries where larval control and insecticide spraying of dwellings with dichlorodiphenyltrichloroethane (DDT) resulted in elimination of malaria from large areas of the globe [1,2]. EIR values are used to quantify the impact of insecticide-treated bed nets (ITNs), indoor residual spraying (IRS), and source reduction (SR) on malaria transmission. This analysis is extended by evaluating whether available vector control tools alone can ultimately eradicate malaria globally.

\section{Why the entomological inoculation rate (EIR)?}

One can measure the intensity of malaria transmission several ways: Table 1 outlines some of these indices, highlighting their advantages and disadvantages [3-9]. Many 
Table 1: Major Indices of Malaria Transmission: Advantages and Disadvantages

\begin{tabular}{|c|c|c|c|}
\hline Index & What is Measured & Advantages & Disadvantages \\
\hline $\begin{array}{l}\text { Entomological Inoculation } \\
\text { Rate (EIR) }\end{array}$ & $\begin{array}{l}\text { Infectious bites per unit time } \\
\text { (usually per year) }\end{array}$ & $\begin{array}{l}\text { Direct reflection of vector } \\
\text { control and } \\
\text { antigametocytocidal drugs }\end{array}$ & $\begin{array}{l}\text { - No standard protocols } \\
\text { - Variability in methodologies } \\
\text { - Few trained specialists }\end{array}$ \\
\hline Parasite Rate (PR) & $\begin{array}{l}\text { Proportion of the population } \\
\text { found to carry asexual } \\
\text { parasites in RBCs; can also } \\
\text { assess gametocyte rates; by } \\
\text { age group }\end{array}$ & $\begin{array}{l}\text { Direct reflection of } \\
\text { inoculations, immunity, and } \\
\text { treatment effectiveness in } \\
\text { humans }\end{array}$ & $\begin{array}{l}\text { - Microscopy "gold standard"; } \\
\text { lacks sensitivity } \\
\text { - Prone to technical efforts } \\
\text { - Changes may occur } \\
\text { following environmental and } \\
\text { control factors }\end{array}$ \\
\hline Annual Parasite Index (API) & $\begin{array}{l}\text { Number of parasite infections } \\
\text { in a well-defined geographical } \\
\text { area; usually per } 1,000 \text { persons } \\
\text { per year }\end{array}$ & $\begin{array}{l}\text { Direct reflection of all } \\
\text { prevention and control effects } \\
\text { on humans }\end{array}$ & $\begin{array}{l}\text { - Depends on active case } \\
\text { detection system, which is } \\
\text { often poor }\end{array}$ \\
\hline Spleen Rate (SR) & $\begin{array}{l}\text { Proportion of children 2-9 } \\
\text { years of age with a palpable } \\
\text { spleen }\end{array}$ & $\begin{array}{l}\text { Non-invasive, indirect way of } \\
\text { measuring impact of malaria } \\
\text { on spleen }\end{array}$ & $\begin{array}{l}\text { - Variability in examiners; } \\
\text { many causes of splenomegaly } \\
\text { - Point prevalence } \\
\text { measurements can vary/ } \\
\text { change rapidly }\end{array}$ \\
\hline
\end{tabular}

of these indices, derived from field and theoretical data, are calculated using assumptions and they are generally not used for evaluating control programmes. The EIR remains the most direct measurement for assessing the effect of anti-vector actions because it quantifies the parasite-infected mosquito pool and its propensity to transmit infectious parasites to the human population.

\section{What is the EIR and how is it measured?}

The EIR is the number of infectious bites per person per unit time, usually measured or expressed per year. It is the product of the human biting rate and the sporozoite rate:

$$
\mathrm{EIR}=\mathrm{MaS}
$$

The human biting rate $(M a)$ is the number of vectors biting an individual over a fixed period of time. $M$ equals the number of Anopheles per person and $a$ equals the average number of persons bitten by one Anopheles in one day. The sporozoite rate $(S)$ is the fraction of vector mosquitoes present and biting that are considered infectious, i.e. Anopheles with sporozoites in their salivary glands [3,10]. Reducing any of these values would decrease the EIR. Several methods measure the human biting rate, including using "capturers" (human landing catches), pyrethrum spray catches, exit trap collections, and CDC light traps [11]. Many errors can emerge in estimating both the human biting rate and sporozoite rate. These result from variation in method used, attraction of mosquitoes to the capturer, and diligence of the technical teams [12].

The 2009 review by Kelly-Hope and McKenzie of annual $P$. falciparum (APf) EIRs illustrates substantial gaps in the EIR data across Africa [13]. APf EIR estimates were available from only 23 of the 54 African countries, with $56 \%$ of the measures from four countries (Kenya, Burkina Faso, Tanzania, and The Gambia) [13]. Figure 1 shows that there can be huge variation in the EIR at the same geographic location, from village to country scale, even when seasonality of transmission is taken into account; for example, Tanzania shows an EIR variation of $>10$ times in the same area [13]. Lack of consistently used, standard EIR measurement methods means that two researchers may measure the EIR in the exact same location and time frame, yet calculate greatly different values.

Numerous factors influence the EIR, including temperature, altitude, rainfall, and urbanization [3]. In general, the EIR is directly proportional to temperature because heat accelerates the sporogonic cycle, the time necessary for ingested gametocytes to develop into infectious sporozoites. The optimal temperature for malaria transmission is $25-27^{\circ} \mathrm{C}$ and an average monthly relative humidity above $60 \%$ [14]. For the same reason, the EIR is inversely proportional to altitude because temperature decreases as altitude increases. The EIR is directly proportional to rainfall because female Anopheles mosquitoes lay their eggs in water. Generally, the EIR is inversely proportional to urbanization because with urbanization comes fewer bodies of water and greater pollution of 


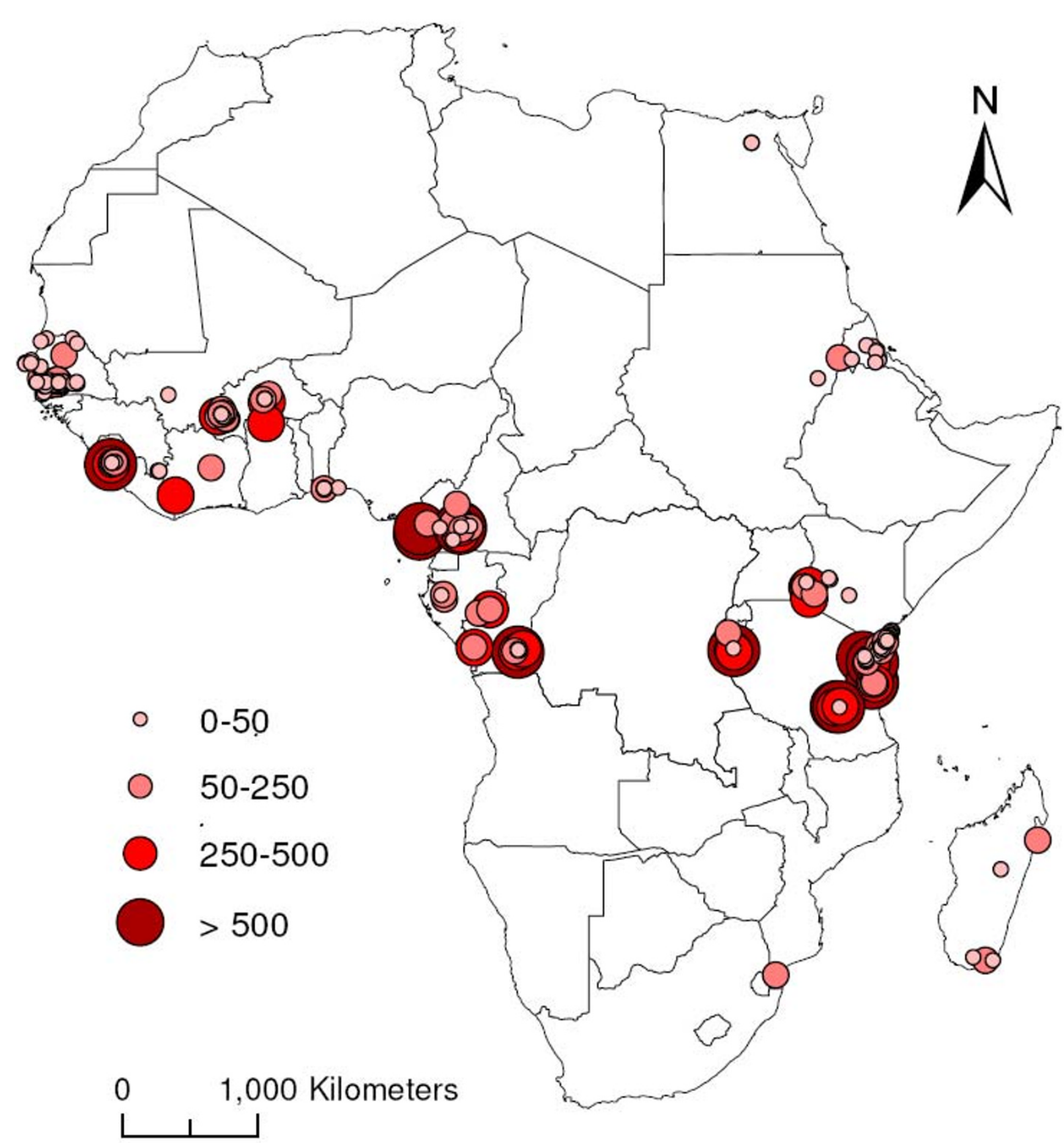

Figure 1 Magnitude and geographical distribution of annual Plasmodium falciparum EIR estimates across Africa between 1980 and 2004

water sources [15]. Therefore, tropical areas with warm temperature, heavy rainfall, high humidity, and efficient Anopheles vectors are ideal for malaria transmission [16]. These factors explain a large part of the variability in the EIRs across Africa.

An adult mosquito's lifespan is particularly important to transmit malaria. The mosquito must survive long enough for the parasite to complete sporogonic development from the point where gametocytes are ingested with the blood meal to the time when infectious sporozoites appear in the salivary glands. This process typically takes 10 days for P. falciparum [2]. Therefore, decreasing the lifespan of mosquitoes substantially decreases the EIR.

\section{Vector control interventions against malaria}

Lacking widespread use of transmission-blocking drugs or vaccines, vector control remains the preferred strategy 
for reducing malaria transmission. It is the only available method "capable of bringing intense or moderate transmission down to the low levels where elimination is within reach" [17]. Insecticide-treated nets (ITNs), indoor residual spray (IRS), and source reduction (SR) are the major vector control tools. Certain tools are more appropriate depending on the mosquito's behaviour and environment. All interventions require careful planning, trained staff for implementation, rigorous supervision and evaluation, free or low-cost access and sustainability [18].

\section{Methods for evaluating the effect of vector control on EIRs}

The analysis in this study is based primarily on a literature search using PubMed, Web of Science ${ }^{\mathrm{SM}}$, and Scopus $^{\mathrm{Tm}}$ for papers on EIR and ITN, IRS, or SR. Variations of these terms and different combinations were used when conducting the literature search. Once papers were found, the references were searched. Active researchers were contacted and asked about unpublished reports and past or on-going work. Studies were excluded if they did not have a control group for comparison with interventions or if they used methods other than ITN, IRS or SR. EIR was calculated as the product of the mean human biting rate multiplied by the mean sporozoite rate. The human biting rate and sporozoite rate were not reported separately in each study.

A total of eight vector control intervention studies were found that measured the EIR: four ITN studies [19-22], one IRS study [23], one SR study [24], and two studies that had separate ITN and IRS intervention groups $[25,26]$. All of the studies included a separate control group that did not receive the intervention, and the researchers took measurements from the control and the intervention groups at the same time. The studies reported different time frames for measuring the mean biting rate, either per night, month, season, or year. The different EIR values could not be directly compared, so percent differences in EIR were calculated between the intervention groups and the control groups to estimate the effects of the interventions. The Garki project was the only study that reported coverage values for intervention methods. Among all villages and rounds of the Garki project, coverage varied from $74 \%$ to $100 \%$. In villages selected for follow up, coverage averaged $99 \%$ and varied, among villages and rounds, from $84 \%$ to $100 \%$. The other seven studies did not report levels of coverage. Due to inadequate information in the reports, the studies were not weighted based on number of measurements, duration, or quality.

Three studies had EIR measurements for more than one year. For these studies, an average of the control group EIR and an average of the intervention group EIR data were calculated. These two averages were compared to calculate the percent difference in EIR between the control group and intervention group. The same method was used to analyse the data from the study that had two intervention groups and took EIR measurements for two years. In the two studies with ITN and IRS intervention groups, each group was compared to the control group and analysed separately.

\section{Results}

Insecticide-treated nets (ITN)

Six studies, performed in Tanzania, Kenya, and the Solomon Islands, measured the EIR with and without an ITN intervention. Table 2[19-22,25,26] summarizes these ITN studies. Two of the ITN studies collected EIR data for two consecutive years, Tanzania from 1995-1996 [25] and Kenya from 1990-1991 [22]. Both of these studies saw a significantly greater decrease in EIR between the ITN and control villages in the second year $(90 \%$ lower in Tanzania and $75 \%$ lower in Kenya) compared to that in the first year (42\% higher in Tanzania and 55\% lower in Kenya). Interestingly, the first year of the Tanzania study showed an increase in the ITN group's EIR compared to the control group. Increased compliance from the community during the second year, or perhaps greater experience with treating the nets and implementing the intervention, serve as possible explanations for greater EIR reduction in the second year of the studies.

\section{Indoor residual spraying (IRS)}

Table $3[23,25,26]$ summarizes the three studies that used IRS and measured the impact on the EIR. Both the Tanzania [25] and Solomon Islands [26] studies had one community that received ITNs and one that received IRS (in addition to the control community). These studies are particularly valuable because they measure the impact of two vector control methods on the EIR. The areas given ITNs and IRS had similar populations and locations, allowing direct comparison of the impact of the two interventions. In the second year of the Tanzania study, ITNs caused a $90 \%$ decrease in EIR and IRS a $93 \%$ decrease, both highly significant; the ITN and IRS effects did not differ. The Solomon Islands study had a significantly greater EIR reduction in the ITN areas, 94\% relative to the control, compared to the IRS areas, 56\%. These were the only two studies found that directly compared the impact of ITN and IRS on the EIR in the same place at the same time. Therefore, there is not enough evidence to generalize and determine which intervention has the greatest effect on the EIR.

\section{Source reduction (larval control)}

Only one study, in Dar es Salaam, measured EIR differences tied to source reduction. The control area had an 
Table 2: EIR Studies Tied to Insecticide Treated Bed Net Intervention

\begin{tabular}{|c|c|c|c|c|c|}
\hline $\begin{array}{l}\text { Location/Year Study Done/ } \\
\text { Reference }\end{array}$ & Insecticide & Mosquito & Method & EIR & Parasite Rate \\
\hline $\begin{array}{l}\text { Tanzania: highland hamlets } \\
\text { (altitudes } 784-1148 \mathrm{~m} \text { ) and } \\
\text { lowland hamlets } \\
(199-300 \mathrm{~m} \text { ) } \\
\text { October } 1998 \text {-August } 2000 \\
\text { [20] }\end{array}$ & $\begin{array}{l}{[0.02] \mathrm{g} \text { alphacypermethrin/ }} \\
\mathrm{m}^{2} \\
\text { nets not re-treated during } \\
\text { study }\end{array}$ & $\begin{array}{l}\text { An. gambiae s.l., An. funestus } \\
\text { and An.marshallii s.l. }\end{array}$ & $\begin{array}{l}\text { light traps, pyrethrum spray, } \\
\text { window exit traps and ELISA }\end{array}$ & $\begin{array}{l}\text { Infectious bites/person/year } \\
\text { Highland: } \\
\text { Control = } 10.4 \text { ITN = } 3.2 \\
\text { Lowland: } \\
\text { Control = } 148.6 \text { ITN = } 37.5 \\
\\
\text { Highland = } \\
\text { 69\% Reduction } \\
\text { Lowland = } \\
\text { 75\% Reduction }\end{array}$ & $\begin{array}{l}\text { Highlands: } \\
6 \text { months- } 2 \text { years: } \\
\text { Control = 54.1\% ITN = 31.4\% } \\
\text { 2-5 years: } \\
\text { Control = 73\% ITN = 44.3\% } \\
\text { 6-12 years: } \\
\text { Control = 67.7\% ITN = 49.4\% } \\
\text { Lowlands: } \\
6 \text { months- } 2 \text { years: } \\
\text { Control = 82.9\% ITN = 63.1\% } \\
\text { 2-5 years: } \\
\text { Control = 88.8\% ITN = 78.3\% } \\
\text { 6- } 12 \text { years: } \\
\text { Control = 83.3\% ITN = 80.6\% } \\
\text { Highlands = 36\% Reduction } \\
\text { Lowlands }=\mathbf{1 3} \% \text { Reduction }\end{array}$ \\
\hline $\begin{array}{l}\text { Lake Victoria shore in Western } \\
\text { Kenya } \\
\text { January 1997-February } 2000 \\
\text { [19] }\end{array}$ & $\begin{array}{l}{[0.5] \mathrm{g} \text { permethrin } / \mathrm{m}^{2}} \\
\text { nets re-treated every 6-11 } \\
\text { months }\end{array}$ & An. gambiae and An. funestus & $\begin{array}{l}\text { pyrethrum spray sheet } \\
\text { collection and ELISA }\end{array}$ & $\begin{array}{l}\text { Infectious bite/person } / \text { month } \\
\text { Control }=0.93 \\
\text { ITN }=0.08 \\
\mathbf{9 1 \% ~ R e d u c t i o n ~}\end{array}$ & Not reported \\
\hline $\begin{array}{l}\text { North East Tanzania } \\
\text { 1997-1998 [21] }\end{array}$ & $\begin{array}{l}{[0.02] \mathrm{g} \text { alphacypermethrin/ }} \\
\mathrm{m}^{2} \text { or }[0.1] \mathrm{g} \\
\text { lambdacyhalothrin } / \mathrm{m}^{2}\end{array}$ & $\begin{array}{l}\text { An. gambiae s.l., An. funestus, } \\
\text { An. marshallii and } c x . \\
\text { quinquefasciatus }\end{array}$ & light traps and ELISA & $\begin{array}{l}\text { Infectious bites/person/night } \\
\text { Control = } 3.24 \\
\text { alphacypermethrin }=0.153 \\
\text { lambdacyhalothrin }=0.140 \\
\text { alphacypermethrin }=\mathbf{9 5 \%} \\
\text { Reduction } \\
\text { lambdacyhalothrin }=\mathbf{9 7} \% \\
\text { Reduction }\end{array}$ & $\begin{array}{l}\text { Rates of re-infection with } \\
\text { asexual malaria parasites after } \\
\text { treatment with } \\
\text { chlorproguanil-dapsone: } \\
\text { Control }=30.8 \% \\
\text { alphacypermethrin }=8.0 \% \\
\text { lambdacyhalothrin }=7.5 \% \\
\text { alphacypermethrin }=\mathbf{7 4 \%} \\
\text { Reduction } \\
\text { lambdacyhalothrin }=\mathbf{7 6} \% \\
\text { Reduction }\end{array}$ \\
\hline
\end{tabular}


Table 2: EIR Studies Tied to Insecticide Treated Bed Net Intervention (Continued)

\begin{tabular}{|c|c|c|c|c|c|}
\hline $\begin{array}{l}\text { North-east Tanzania } \\
\text { 1995-1996 [25] }\end{array}$ & $\begin{array}{l}\text { [0.01] g lambdacyhalothrin/ } \\
\mathrm{m}^{2} \text { for two villages } \\
{[0.02] \text { g lambdacyhalothrin/ }} \\
\mathrm{m}^{2} \text { for two villages } \\
\text { nets re-treated after } 7 \text { months }\end{array}$ & An. gambiae and An. Funestsus & $\begin{array}{l}\text { light traps, window exit traps, } \\
\text { pyrethrum spray collection } \\
\text { and ELISA }\end{array}$ & $\begin{array}{l}\text { Infectious bites/person/night } \\
\text { 1995: } \\
\text { Control = } 1.04 \\
\text { ITN }=1.48 \\
1996: \\
\text { Control }=0.773 \\
\text { ITN }=0.08 \\
1995=\mathbf{4 2} \% \text { Increase } \\
1996=\mathbf{9 0} \% \text { Reduction }\end{array}$ & Not reported \\
\hline $\begin{array}{l}\text { Western Kenya } \\
\text { March-June } 1990 \text { and } 1991 \\
\text { (high transmission season) } \\
\text { [22] }\end{array}$ & $\begin{array}{l}{[0.5] \mathrm{g} \text { permethrin } / \mathrm{m}^{2}} \\
\text { nets re-treated October } 1990\end{array}$ & An. Gambiae s.s. & $\begin{array}{l}\text { night biting collections and } \\
\text { ELISA }\end{array}$ & $\begin{array}{l}\text { Infectious bites/person/night } \\
1990 \text { high transmission } \\
\text { season: } \\
\text { Control }=0.47 \text { ITN }=0.21 \\
1991 \text { high transmission } \\
\text { season: } \\
\text { Control }=0.36 \text { ITN }=0.09 \\
1990=\mathbf{5 5} \% \text { Reduction } \\
1991=\mathbf{7 5} \% \text { Reduction }\end{array}$ & $\begin{array}{l}\text { Incidence of Plasmodium } \\
\text { falciparum parasitemia } \\
\geq 2,500 / \mathrm{mm}^{2} \text { in children less } \\
\text { than six years old } \\
1990 \text { high transmission } \\
\text { season: } \\
\text { Control = } 135 \text { (94) ITN = } 77 \\
(53) \\
1991 \text { high transmission } \\
\text { season: } \\
\text { Control = } 64(82) \text { ITN = 51(64) } \\
1990=\mathbf{4 3 \%} \text { Reduction } \\
1991=\mathbf{2 0} \% \text { Reduction }\end{array}$ \\
\hline $\begin{array}{l}\text { Northern Guadalcanal, } \\
\text { Solomon Islands } \\
\text { November 1987-June } 1988 \\
\text { [26] }\end{array}$ & $\begin{array}{l}\text { [0.5] g permethrin } / \mathrm{m}^{2} \\
\text { nets re-treated August } 1987\end{array}$ & An. farauti and An. Puctulatus & $\begin{array}{l}\text { Human landing catch and } \\
\text { ELISA }\end{array}$ & $\begin{array}{l}\text { Infectious bites/person/night } \\
\text { Control }=2.204 \\
\text { ITN }=0.129 \\
\text { 94\% Reduction }\end{array}$ & 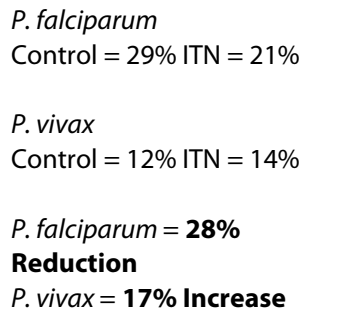 \\
\hline
\end{tabular}


Table 3: EIR Studies Tied to Indoor Residual Spray Intervention

\begin{tabular}{|c|c|c|c|c|c|}
\hline $\begin{array}{l}\text { Location/Year } \\
\text { Study Done/ } \\
\text { Reference }\end{array}$ & Insecticide & Mosquito & Method & EIR & Parasite Rate \\
\hline $\begin{array}{l}\text { North-east } \\
\text { Tanzania } \\
\text { 1995-1996 [25] }\end{array}$ & $\begin{array}{l}{[0.03] \mathrm{g}} \\
\text { lambdacyhalothri } \\
\mathrm{n} / \mathrm{m}^{2} \\
\text { re-sprayed } 7-8 \\
\text { months after } \\
\text { initial spray }\end{array}$ & $\begin{array}{l}\text { An. gambiae and } \\
\text { An. funestsus }\end{array}$ & $\begin{array}{l}\text { light traps, } \\
\text { window exit traps, } \\
\text { pyrethrum spray } \\
\text { collection and } \\
\text { ELISA }\end{array}$ & $\begin{array}{l}\text { Infectious bites/ } \\
\text { person/night } \\
\text { 1995: } \\
\text { Control = } 1.04 \\
\text { IRS = } 0.98 \\
\text { 1996: } \\
\text { Control = } 0.773 \\
\text { IRS = } 0.057 \\
\text { 1995 = 5.7\% } \\
\text { Reduction } \\
\text { 1996= 93\% } \\
\text { Reduction }\end{array}$ & Not reported \\
\hline $\begin{array}{l}\text { Northern } \\
\text { Guadalcanal, } \\
\text { Solomon Islands } \\
\text { November 1987- } \\
\text { June } 1988 \text { [26] }\end{array}$ & [2] g DDT/m² & $\begin{array}{l}\text { An. farauti and An. } \\
\text { puctulatus }\end{array}$ & $\begin{array}{l}\text { Human landing } \\
\text { catch and ELISA }\end{array}$ & $\begin{array}{l}\text { Infectious bites/ } \\
\text { person/night } \\
\text { Control }=2.204 \\
\text { IRS }=0.9675 \\
\mathbf{5 6} \% \text { Reduction }\end{array}$ & $\begin{array}{l}\text { P. falciparum } \\
\text { Control = } 29 \% \\
\text { IRS }=46 \% \\
\text { P. Vivax } \\
\text { Control = 12\% } \\
\text { IRS = 9\% } \\
P . \text { falciparum = } \\
\mathbf{5 9} \% \text { Increase } \\
P . \text { vivax = } \\
\mathbf{2 5} \% \text { Reduction }\end{array}$ \\
\hline $\begin{array}{l}\text { Garki, Nigeria } \\
\text { September } 1969- \\
\text { February } 1976 \\
\text { [23] }\end{array}$ & $\begin{array}{l}\text { [2] g propoxur/m² } \\
\text { re-sprayed every } \\
2 \text { months }\end{array}$ & $\begin{array}{l}\text { An. Gambiae s.l. } \\
\text { and An. funestus }\end{array}$ & $\begin{array}{l}\text { Human landing } \\
\text { collection, } \\
\text { pyrethrum spray } \\
\text { collection, exit } \\
\text { trap collection, } \\
\text { outdoor resting } \\
\text { collection and } \\
\text { ELISA }\end{array}$ & $\begin{array}{l}\text { Infectious bites/ } \\
\text { person/wet } \\
\text { season (wet } \\
\text { season 1972: May } \\
\text { 22-Oct. } 22 \text { 1973: } \\
\text { June 18-Nov. 4) } \\
\text { Control: } \\
\text { Village 1: } \\
\text { 1972 = 17 1973= } \\
21 \\
\text { Village 2: } \\
\text { 1972 = 25 1973= } \\
\text { 28 } \\
\text { IRS: } \\
\text { Village 3: } \\
\text { 1972 = } 01973= \\
\text { 10 } \\
\text { Village 4: } \\
\text { 1972 = } 31973=4 \\
\text { 1972 = 93\% } \\
\text { Reduction } \\
\text { 1973 = } \\
\mathbf{7 1 . 4 \% R e d u c t i o n ~}\end{array}$ & $\begin{array}{l}\text { P. falciparum } \\
\text { Control } \\
1972=43.3 \% \\
1973=47.5 \% \\
\text { IRS } \\
1972=36.8 \% \\
1973=35.0 \% \\
P . \text { malariae } \\
\text { Control } \\
1972=13.0 \% \\
1973=11.19 \% \\
\text { IRS } \\
1972=13.3 \% \\
1973=13.3 \% \\
P . \text { falciparum } \\
1972= \\
\text { 15\% Reduction } \\
1973= \\
\mathbf{2 6} \% \text { Reduction } \\
P . \text { malariae } \\
1972=\mathbf{2 . 3} \% \\
\text { Increase } \\
1973=\mathbf{1 9} \% \\
\text { Increase }\end{array}$ \\
\hline
\end{tabular}


annual EIR of 1.06 (0.64-1.77) and the area that received the microbial larvicide Bacillus thuringiensis israeliensis (Bti) had an annual EIR of 0.56 (0.43-0.77). There was a lower EIR reduction (47\%) due to SR compared to the ITN and IRS studies [24]. However, SR is likely to be particularly effective in urban areas, where breeding places are man-made and can be identified, mapped, and treated [27]. SR should receive increasing attention for malaria control because more than half of the African population is expected to live in urban and peri-urban areas by 2030 [24].

\section{EIR analysis}

In each of these eight studies, the malaria vector population size and sporozoite rates decreased, causing a great decrease in the EIR. The studies used different time frames to measure EIR; each study reported the defined EIR as infective bites per person - per year, season, month, or night.

One approach to analysing the data would be to standardize all the EIRs to one year. For example, in Molineaux's and Gramiccia's Garki project data, in 1973 one village that received ITNs had 28 infectious bites per person per wet season. The wet season in 1973 lasted 139 days [23]. Therefore, if the EIR were calculated for the entire year, it would be 73.6 infectious bites per person per year. However, EIR is highest during the rainy season. If EIRs taken during the rainy season were used and if these values were extended to represent the entire year, the calculations would grossly overestimate the annual EIR. Additionally, the EIRs between studies could not be directly compared because the study areas have different climate, altitude, and population density.

To avoid this problem, EIR percent changes based on values with and without the implementation of vector control interventions were calculated. Figure 2 summarizes the EIR percent reduction data from the eight studies in this review. All the studies that lasted for more than one year, aside from the Garki project, had a greater reduction in the EIR the second year. The 1998, Tanzania study had a higher EIR value in the intervention group than the control group and it is an outlier from the rest of the data [25]. The other studies showed a large percent EIR reduction in their vector control intervention groups, however none reached $100 \%$ reduction.

The EIRs calculated in this study were compared to the report by Beier et al, which relates EIRs to parasite rates [28]. Beier et al reported that only annual EIRs less than one could reduce parasite rates to levels that could interrupt malaria transmission. They concluded that it may not be possible to achieve dramatic decreases in the prevalence of $P$. falciparum infection at sites in Africa, unless control measures sustainably reduce EIRs to levels well below one infective bite per person per year [28].
Putting aside previously mentioned concerns about extending the EIRs measured per night, month, or season to represent the entire year, the annual EIR for all the studies in this review were calculated to relate these studies to the findings of Beier et al. Of all eight studies, only the Garki project using IRS with propoxur, a carbamate insecticide, reduced the annual EIR to less than one infective bite per person (Figure 3) [23]. However, the Garki project interventions only caused temporary reduction of the EIR. In 1972, the EIR was reduced to zero, but despite re-spraying houses every two months, the EIR increased to ten the following year [23]. Therefore, the only intervention study that decreased the EIR to $<1$ did not maintain such a level for more than one year. Based on these data, current vector control methods are not enough to eradicate malaria. ITNs, IRS, and SR are imperfect, but researchers must continue using and improving them.

\section{Integrated vector management (IVM)}

Malaria researchers believe that IVM is an effective strategy because it uses two or more vector control methods, with each method targeting a setting most susceptible to that intervention. Although IRS, ITN, and SR are all effective individually, they complement each other and have a synergistic impact when used together [29]. IVM involves a "rational decision-making process for the optimal use of resources for vector control" [30]. It requires reconsidering the combination of vector control methods over time, as the environment, epidemiology, and resources change. IVM is not limited to controlling malaria. In 2004, the World Health Organization recommended IVM globally for the control of all vector-borne diseases [30].

IVM programmes have brought great reductions in malaria transmission. Killeen et al created a mathematical model to predict the impact of IVM on EIR. Their model predicts a 15- to 25-fold reduction in EIR when using ITNs and larval control. Their model predicts that ITNs and IRS are the most effective tools available for reducing the EIR; source reduction amplifies the results. Despite their dramatic predicted impact on the EIR, the simulated integrated control programmes in the model by Killeen $e t$ al failed to reduce the EIR to less than one at any of their sites [5].

The work of Fillinger et al [31] in the western highlands of Kenya is the first study that measures the impact of an IVM approach directed at both larval and adult mosquitoes. Their study's control groups had EIRs of 10-12 infectious bites per person per year. With ITNs, the annual EIR dropped to 1.68 infectious bites per person. Once the researchers added microbial larvicide to ITNs, the annual EIR dropped to 0.39 infectious bites per person, a 73\% reduction [31]. Therefore, using ITNs and SR together reduced the annual EIR to less than one (Figure 


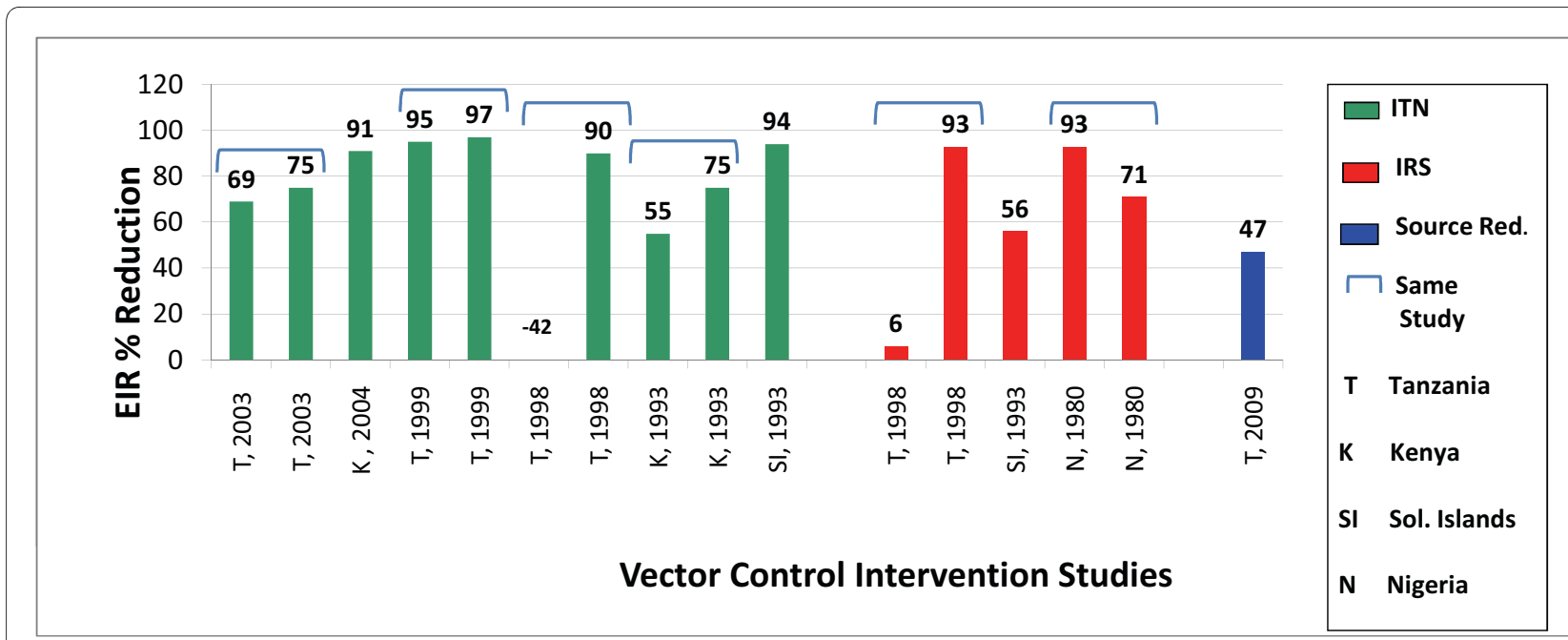

Figure 2 Entomological inoculation rate percent reduction by vector control intervention.

4). The parasite prevalence was similar in all the groups at baseline measurements. There was a significantly lower prevalence of new infections in the intervention group that received larvicide $(7.0 \%, 95 \%$ confidence interval 4.6\%-10.7\%) compared to the group that did not receive larvicide (12.8\%, 95\% confidence interval 9.7\%-15.9\%).

These studies illustrate that an integrated vector approach can meaningfully reduce EIR and that larval control amplifies the effect of adult vector control. Vector control interventions do not sustainably decrease EIR values low enough to effectively drive down malaria prevalence. However, IVM organizes these tools to make the greatest impact on malaria transmission, while researchers may invest time in developing new methods to fight the disease.

\section{Conclusions}

\section{Conclusions and future research directions}

This is the first review that links vector control methods to the EIR. The results illustrate that for areas with

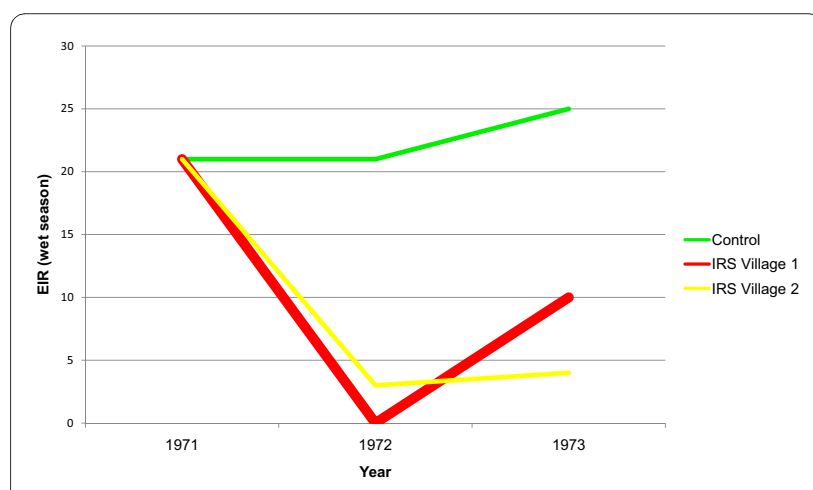

Figure 3 Entomological inoculation rates following insecticide residual spraying in Garki, Nigeria, 1971-1972. intense transmission, current vector control tools are not enough to eradicate malaria. Use of ITNs, IRS, or SR individually will not decrease the annual EIR low enough to assure consistently significant and sustained reductions in malaria parasite prevalence. This analysis is based on the assumption that an EIR below one is needed to interrupt malaria transmission, though caution is required when following this assumption. Through conducting this review, gaps were found in the literature and several recommendations are included:

- Researchers should conduct more EIR studies in relation to vector control interventions; there are only nine studies that measure the impact of vector control interventions on the EIR.

- Researchers must standardize EIR methods to allow comparisons between studies. EIR percent changes were calculated for comparisons of different studies. If researchers agreed on a standard EIR time frame measurement, then individuals could directly compare different studies.

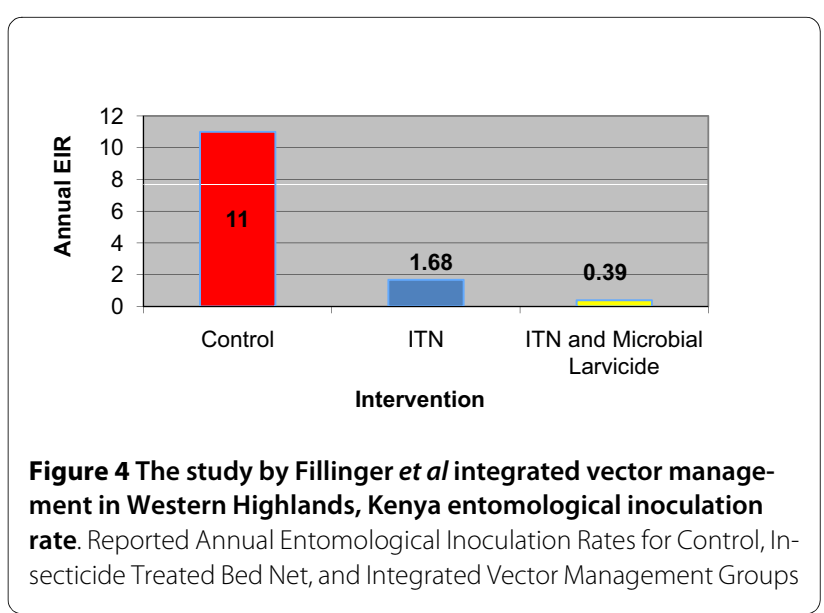


- Researchers should include background information about communities in their studies. The EIR is influenced by factors such as altitude, population density, rainfall, socio-cultural attitudes and behaviour, as well as current malaria control actions and their impact on human infection and disease. Additionally, researchers should include information about the coverage in intervention groups. Among the studies in this paper, the Garki project was the only study that reported level of coverage. These details are often missing from articles on EIR studies and they are essential for comparing different studies.

- It is necessary to conduct long term ( $>1$ year) studies to measure the sustainability of the intervention's impact. If researchers had conducted the Garki project for only one year, they would have a false sense of confidence in the impact of IRS for their site.

- Increased research in source reduction and integrated vector management studies are strongly advised, particularly for urban, peri-urban, and epidemic-prone areas. Integrated vector management provides an approach that makes the most use out of existing tools. Only two studies were found that used
ITNs and SR, one of which was a theoretical analysis [5,31]. Researchers should conduct an IVM study with all three vector control interventions to measure their additive or synergistic effect.

- Measurement of the EIR should also be coordinated with parasitological, clinical, and meteorological indices, assessed at the same time and in the same place to reflect the most accurate picture of transmission. These factors are interrelated, however, researchers have yet to conduct a study that takes all these factors into account.

- There must be a focus on building entomological operational and research capacity. Figure 5 illustrates vector surveillance capacities in national malaria control programmes and research institutions in 38 African countries. Only South Africa, Algeria, and Cameroon have a high entomology capacity [32]. This figure is based on data from 2006, so there may have been improvements since then. The President's Malaria Initiative (PMI), the Global Fund for AIDS, Tuberculosis and Malaria, and other public health programmes have made major investments in vector control interventions, yet we lack trained researchers

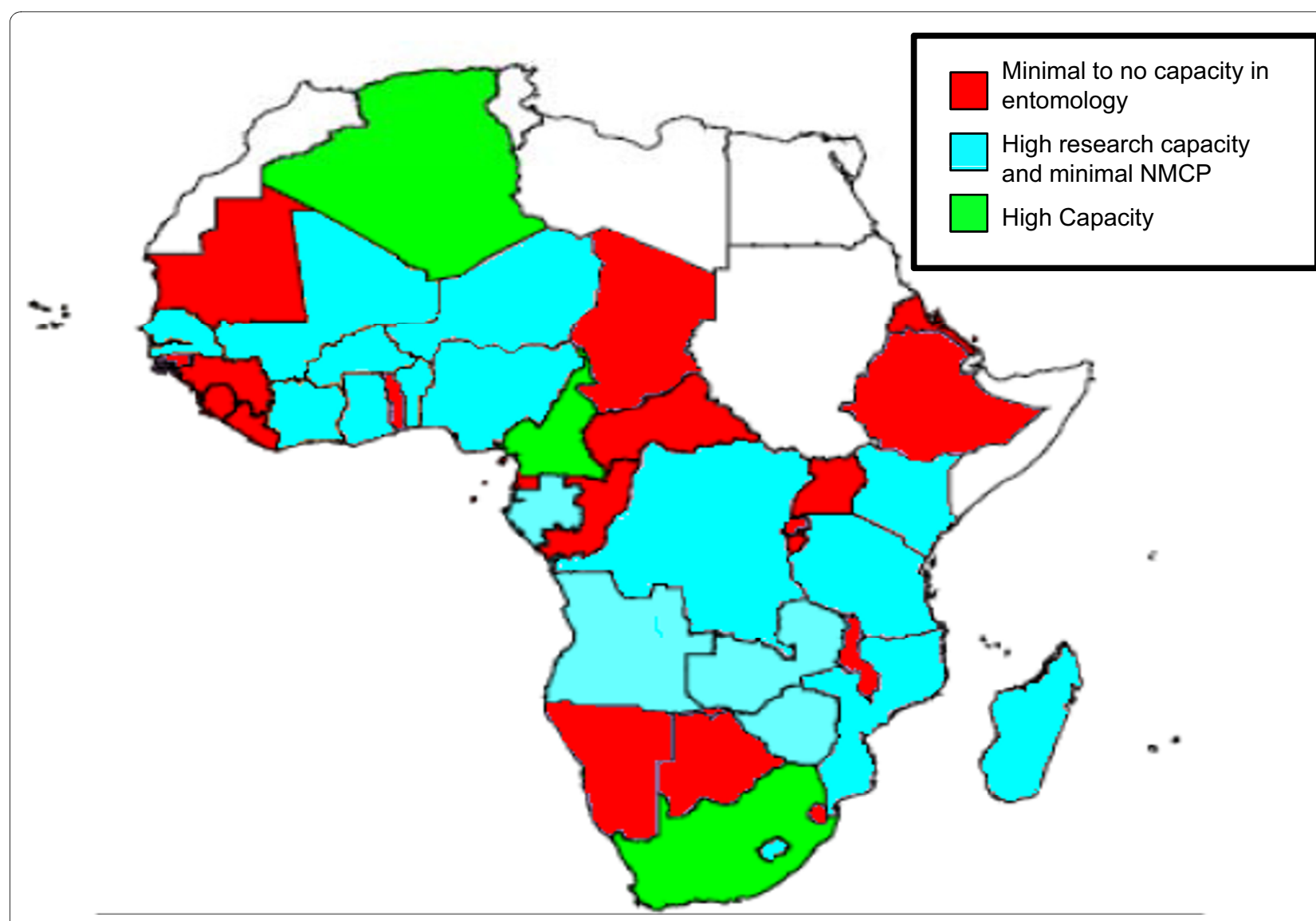

Figure 5 Vector surveillance capacities in National Malaria Control Programmes (NMCP) and research institutions in 38 African Countries. Adapted from African Network on Vector Resistance: ANVR Newsletter Issue No. 1, 2006 
to conduct the work. Accomplishing the goals defined by these ambitious programmes requires a highly skilled, supervised, and supported team of entomology and vector control specialists in addition to a large cadre of scientists, public health, and operational specialists in all malaria disciplines.

When drawing conclusions from EIR studies, one must keep in mind the difficulty in measuring EIR. Many factors influence EIR, including location, time of year, and measurement method. Additionally, EIR studies may not measure the full impact of a particular intervention because vector control measures have increased impact over time. Although measuring EIR can be difficult, expensive, and time consuming, it remains the most direct measurement for assessing the effect of vector control interventions.

\section{Competing interests}

The authors declare that they have no competing interests.

\section{Authors' contributions}

AMS identified data sources, carried out data analysis, and wrote the first draft of the manuscript. JGB conceived the idea for the research and contributed significantly to formatting and editing the manuscript. FEM critically revised the manuscript. All authors read and approved the final manuscript.

\section{Acknowledgements}

We are grateful to the following individuals for their contributions to this paper: John Beier, Ulrike Fillinger, Patricia Graves, Robert Gwadz, Louise Kelly-Hope, Gerald Killeen, Tovi Lehmann, Christian Lengeler, Alicia Livinski, Jose Ribeiro, Yesim Tozan, Cecile Viboud and Anne White-Olson.

\section{Author Details}

Division of International Epidemiology and Population Studies, Fogarty International Center, National Institutes of Health, Bethesda, MD, USA

Received: 13 December 2009 Accepted: 12 May 2010

Published: 12 May 2010

\section{References}

1. Implementation of indoor residual spraying of insecticides for malaria control in the WHO African Region report [http://www.afro.who.int/ vbc/reports/ report on the implementation of irs in the african region 2007.pdf

2. Killeen GF, Fillinger U, Kiche I, Gouagna LC, Knols BG: Eradication of Anopheles gambiae from Brazil: lessons for malaria control in Africa? Lancet Infect Dis 2002, 2:618-627.

3. Warrell DA, Gilles HM: Essential malariology Fourth edition. New York: Arnold; 2002

4. Fontenille $D$, Simard F: Unravelling complexities in human malaria transmission dynamics in Africa through a comprehensive knowledge of vector populations. Comp Immunol Microbiol Infect Dis 2004, 27:357-375

5. Killeen GF, McKenzie FE, Foy BD, Schieffelin C, Billingsley PF, Beier JC: The potential impact of integrated malaria transmission control on entomologic inoculation rate in highly endemic areas. Am J Trop Med Hyg 2000, 62:545-551.

6. Smith DL, Smith TA, Hay SI: Measuring malaria for elimination. In Shrinking the Malaria Map: A Prospectus on Malaria Elimination Edited by: Feachem RGA, Phillips AA, Targett GA. San Francisco: The Global Health Group; 2009:108-126.

7. Smith DL, McKenzie FE: Statics and dynamics of malaria infection in Anopheles mosquitoes. Malar J 2004, 3:13.

8. Smith DL, Guerra CA, Snow RW, Hay SI: Standardizing estimates of the Plasmodium falciparum parasite rate. Malar J 2007, 6:131.
9. Smith DL, McKenzie FE, Snow RW, Hay SI: Revisiting the basic reproductive number for malaria and its implications for malaria control. PLOS Biol 2007, 5:e42.

10. Snow RW, Marsh K: The consequences of reducing transmission of Plasmodium falciparum in Africa. Adv Parasitol 2002, 52:235-264.

11. Manual on Practical Entomology in Malaria. Part II: Methods and Techniques. Geneva: World Health Organization; 1975.

12. Fontenille D, Meunier JY, Nkondjio CA, Tchuinkam T: Use of circumsporozoite protein enzyme-linked immunosorbent assay compared with microscopic examination of salivary glands for calculation of malaria infectivity rates in mosquitoes (Diptera: Culicidae) from Cameroon. J Med Entomol 2001, 38:451-454

13. Kelly-Hope LA, McKenzie FE: The multiplicity of malaria transmission: a review of entomological inoculation rate measurements and methods across sub-Saharan Africa. Malar J 2009, 8:19.

14. Pampana E: A textbook of malaria eradication London: Oxford University Press; 1969.

15. Robert V, Macintyre K, Keating J, Trape JF, Duchemin JB, Warren M, Beier $J C$ : Malaria transmission in urban sub-Saharan Africa. Am J Trop Med Hyg 2003, 68:169-176.

16. Breman JG: The ears of the hippopotamus: manifestations, determinants, and estimates of the malaria burden. Am J Trop Med Hyg 2001:1-11.

17. Enayati A, Lines J, Maharaj R, Hemingway J: Suppressing the vector. In Shrinking the Malaria Map: A Prospectus on Malaria Elimination Edited by: Feachem RGA, Phillips AA, Targett GA. San Francisco: The Global Health Group; 2009:140-154.

18. World Health Organization Technical Report Series [http:// malaria.who.int/docs/WHO-TRS-936s.pdf]

19. Lindblade KA, Eisele TP, Gimnig JE, Alaii JA, Odhiambo F, ter Kuile FO, Hawley WA, Wannemuehler KA, Phillips-Howard PA, Rosen DH, et al: Sustainability of reductions in malaria transmission and infant mortality in western Kenya with use of insecticide-treated bednets: 4 to 6 years of follow-up. JAMA 2004, 291:2571-2580.

20. Maxwell CA, Chambo W, Mwaimu M, Magogo F, Carneiro IA, Curtis CF: Variation of malaria transmission and morbidity with altitude in Tanzania and with introduction of alphacypermethrin treated nets. Malar J 2003, 2:28

21. Maxwell CA, Myamba J, Njunwa KJ, Greenwood BM, Curtis CF: Comparison of bednets impregnated with different pyrethroids for their impact on mosquitoes and on re-infection with malaria after clearance of pre-existing infections with chlorproguanil-dapsone. Trans R Soc Trop Med Hyg 1999, 93:4-11.

22. Beach RF, Ruebush TK II, Sexton JD, Bright PL, Hightower AW, Breman JG, Mount DL, Oloo AJ: Effectiveness of permethrin-impregnated bed nets and curtains for malaria control in a holoendemic area of western Kenya. Am J Trop Med Hyg 1993, 49:290-300.

23. Molineaux L, Gramiccia G: The Garki project: research on the epidemiology and control of malaria in the Sudan savanna of West Africa. Geneva: World Health Organization; 1980.

24. Geissbuhler Y, Kannady K, Chaki PP, Emidi B, Govella NJ, Mayagaya V, Kiama M, Mtasiwa D, Mshinda H, Lindsay SW, et al: Microbial larvicide application by a large-scale, community-based program reduces malaria infection prevalence in urban Dar es Salaam, Tanzania. PLoS One 2009, 4:e5107.

25. Curtis CF, Maxwell CA, Finch RJ, Njunwa KJ: A comparison of use of a pyrethroid either for house spraying or for bednet treatment against malaria vectors. Trop Med Int Health 1998, 3:619-631.

26. Hii JL, Kanai L, Foligela A, Kan SK, Burkot TR, Wirtz RA: Impact of permethrin-impregnated mosquito nets compared with DDT housespraying against malaria transmission by Anopheles farauti and An. punctulatus in the Solomon Islands. Med Vet Entomol 1993, 7:333-338.

27. Gu W, Regens JL, Beier JC, Novak RJ: Source reduction of mosquito larval habitats has unexpected consequences on malaria transmission. Proc Natl Acad Sci USA 2006, 103:17560-17563.

28. Beier JC, Killeen GF, Githure Jl: Short report: entomologic inoculation rates and Plasmodium falciparum malaria prevalence in Africa. Am $J$ Trop Med Hyg 1999, 61:109-113.

29. Okech BA, Mwobobia IK, Kamau A, Muiruri S, Mutiso N, Nyambura J Mwatele C, Amano T, Mwandawiro CS: Use of integrated malaria management reduces malaria in Kenya. PLoS One 2008, 3:e4050. 
30. Beier JC, Keating J, Githure JI, Macdonald MB, Impoinvil DE, Novak RJ: Integrated vector management for malaria control. Malar J 2008, 7(Suppl 1):S4

31. Fillinger U, Ndenga B, Githeko A, Lindsay S: Integrated malaria vector control with microbial larvicides and insecticide treated nets in the western Kenyan highlands: a controlled trial. Bull World Health Organ 2009, 87(9):655-65.

32. World Health Organization: Malaria vector surveillance in africa: building up malaria entomology skills at the level of national malaria control programmes is the way forward [http://www.who.int/tdrold/topics/ mol entomology/files/anvr 1.pdf].

doi: $10.1186 / 1475-2875-9-122$

Cite this article as: Shaukat et al., Using the entomological inoculation rate to assess the impact of vector control on malaria parasite transmission and elimination Malaria Journal 2010, 9:122

Submit your next manuscript to BioMed Central and take full advantage of:

- Convenient online submission

- Thorough peer review

- No space constraints or color figure charges

- Immediate publication on acceptance

- Inclusion in PubMed, CAS, Scopus and Google Scholar

- Research which is freely available for redistribution

Submit your manuscript at www.biomedcentral.com/submit
C) Biomed Central 